\title{
Direct reaction of oximes with crotylsarin, cyclosarin, or VX in vitro
}

\author{
G. Becker • A. Kawan • D. Gutzeit · F. Worek • \\ L. Szinicz
}

Received: 27 June 2006 / Accepted: 8 November 2006 / Published online: 7 December 2006

(C) Springer-Verlag 2006

\begin{abstract}
The direct reaction of seven pyridinium oximes with the organophosphorus compounds (OPCs) crotylsarin, cyclosarin, and VX was studied by spectrophotometry. This method allows to quantify different parameters: (a) the half-life times $\left(t_{1 / 2}\right)$ of the oximeOPC reactions on the basis of the changes in the absorption at the zwitterion (betaine) peak maximum, (b) the first- and second-order rate constants $\left(k_{1}, k_{2}\right)$, and (c) the maximum reaction velocities $\left(v_{\text {max }}\right)$. The results of the study show that the reaction velocity of the nerve agents with any of the oximes investigated decreased in the order crotylsarin $>$ cyclosarin $>$ VX. The comparison of the reaction rates of the three therapeutically used oximes (2-PAM, obidoxime, HI 6) with the respective OPC gave the highest rate for crotylsarin and cyclosarin with obidoxime and to a similar degree with HI 6, while in the case of VX the most reactive oxime was HI 6. The reaction velocity of the nerve agents with the monopyridinium oxime 2-PAM was lower as compared to the bispyridinium oximes (obidoxime, HI 6). The results obtained with the two sarin analogues indicate that the direct reaction with 2-PAM, obidoxime, or HI 6 could be used for non-corrosive decontamination purposes, especially, if sensitive biological surfaces like skin, mucous membranes, or wounds are considered. However, in view of the concentrations of nerve agents and oximes, which could be expected during OPC poisoning in man, the maximum reaction velocities would not be high enough to contribute markedly to the detoxication of nerve agents in vivo.
\end{abstract}

G. Becker · A. Kawan · D. Gutzeit · F. Worek $(\bowtie) \cdot$ L. Szinicz Institut für Pharmakologie und Toxikologie der Bundeswehr, Neuherbergstrasse 11, 80937 München, Germany

e-mail: Franzworek@Bundeswehr.org
Keywords Oximes $\cdot$ Crotylsarin $\cdot$ Cyclosarin $\cdot$ VX . Direct reaction

\section{Introduction}

The fatal effect of poisoning by organophosphorus compounds (OPCs) like pesticides or chemical warfare agents is due to inhibition of the active site of the enzyme acetyl-cholinestrase (EC 3.1.1.7). Today it is generally accepted (Volans 1996; Lee 2003) that the treatment of OPC-poisoning is based on the immediate and simultaneous administration of an antimuscarinic (e.g. atropine), a reactivator (pyridinium oximes like 2PAM or obidoxime), and an anticonvulsant (e.g. diazepam). In a biological environment (aqueous solution, $\mathrm{pH}$ 7.4) pyridinium oximes form a zwitterion (betaine) with a high electron density at the $\mathrm{O}$-atome of the oximate group. This enables the oximate to react as a nucleophilic agent and to displace the phosphyl (phosphonyl or posphoryl) residue from the enzyme. Thereby a phosphyloxime (POX) intermediate is generated. Furthermore, oximes are able to react spontaneously with a free OPC also forming a POX. This more or less stable intermediate is decomposed spontaneously into less toxic reaction products.

After the first description of the direct reaction of different PAM isomers with sarin by Green and Saville 1956, various attempts have been made to characterize and to quantify the reaction. However, the studies are hardly to compare, since the authors did not only use different methods, OPCs, and oximes, but also different buffers, $\mathrm{pH}$ values, temperatures, and reactant concentrations (Hackley et al. 1959; Lamb et al. 1965; Okonek 1972; Nenner 1974; Harvey et al. 1986; Waser et al. 
1992). Therefore, experiments were carried out to study the interaction of OPCs and oximes under identical conditions. In a previous communication in this journal we reported upon the direct reaction of seven pyridinium oximes (2-PAM, obidoxime, HS 6, HGA 1, HGG 12, HI 6, and HLö 7) with the OPCs sarin, soman, and tabun (Becker et al. 1997). This work was continued and is presented here giving the results of the interaction studies of the same seven pyridinium oximes with the OPCs cyclosarin, crotylsarin, and VX. Taken together, experiments with 42 different combinations of oximes and OPCs were carried out and described. Since these studies were performed under identical conditions (spectrophotometry, 0.1 M MOPS buffer, $\mathrm{pH} 7.4$ at $25^{\circ} \mathrm{C}$, oxime $15 \mu \mathrm{M}$, nerve agent $1.5 \mathrm{mM}$ ), the results are comparable.

The aim of the work was to elucidate whether the direct reaction could contribute to the therapeutic effect of oxime treatment after OPC-poisoning. Furthermore, there was the question whether the oximes could serve as non-corrosive decontaminating compounds, especially for sensitive biological surfaces like skin, mucous membranes, or wounds.

\section{Materials and methods}

\section{Chemicals}

Crotylmethylphosphonofluoridate (crotylsarin, 97\% pure), cyclohexylmethylphosphonofluoridate (cyclosarin, > 98\% pure), and O-Ethyl S-2-(diisopropylamino)ethyl methylphosphonothiolate (VX, 98\% pure) were made available by the German Ministry of Defence (purity checked by gas chromatography). Morpholinopropanesulfonic acid (MOPS) and pyridinium-2-aldoxime methiodide (2-PAM iodide or pralidoxime iodide) were obtained from Sigma (Deisenhofen, Germany).

HGG 12 (pyridinium, 1-[[3-(benzoyl-pyridinio)methoxy]methyl]-2-[(hydroxyimino)methyl]dichloride or dinitrate) and obidoxime (1,1'-[oxy-bis(methylene)]bis [4-(hydroxyimino)methyl]pyridinium dichloride) were obtained from Merck (Darmstadt, Germany). HI 6 (pyridinium, 1-[[[4-(aminocarbonyl)pyridinio]methoxy]methyl]-2-[(hydroxyimino)methyl]dichloride) was a gift of Dr. J. G. Clement (DRES, Ralston, Alberta, Canada). HLö 7 (pyridinium, 1-[[[4-(aminocarbonyl)pyridinio]methoxy]methyl]-2,4-bis[(hydroxyimino)methyl] dimethanesulfonate) was obtained from J. Braxmeier (Chemisches Laboratorium, Döpshofen, Germany). HGA 1 (3-(N,N-dimethylamino-carbonyloxy)-2-(hydr oxyiminomethyl)-1-methylpyridinium iodide) was synthesized by Dr. H. Eckert (Institut für Organische Chemie I, TU München, Germany), and HS 6 (pyridinium, 1-[[[3-(aminocarbonyl)pyridinio]methoxy]methy 1]-2-[(hydroxyimino)methyl]dichloride) was obtained from Dr. H. Oldiges (Fraunhofer-Institut für Umweltchemie und Ökotoxikologie, Schmallenberg, Germany).

\section{Solutions}

Stock solutions of the oximes $(30 \mu \mathrm{M})$ and OPCs ( $3 \mathrm{mM}$ crotylsarin, cyclosarin, or VX) were freshly prepared in $0.1 \mathrm{M}$ MOPS buffer, $\mathrm{pH} 7.4$ at $25^{\circ} \mathrm{C}$ immediately before use. To facilitate the dispersion and solution of $\mathrm{VX}$ in the buffer, the preparation was shaken for $2 \mathrm{~min}$ by means of a Vortex mixer (Vortex Genie 2, step 6).

\section{UV spectra}

The oxime spectra (250-430 nm) were recorded using a 1-cm quartz cuvette and a UV-VIS Beckman type DU 70 instrument with temperature control. The reference spectrum of $15 \mu \mathrm{M}$ oxime (in the absence of OPC) was determined in $0.1 \mathrm{M}$ MOPS buffer, $\mathrm{pH} 7.4$ at $25^{\circ} \mathrm{C}$. Immediately after mixing of $1.5 \mathrm{ml}$ of oxime solution with $1.5 \mathrm{ml}$ of the OPC stock solution in the quartz cuvette, the reaction spectra, i.e. the time dependent changes of the oxime concentrations were followed at $25^{\circ} \mathrm{C}$ after various reaction time intervals $(0.25$ $540 \mathrm{~min}$ ). At the start of the reaction the final concentrations of each of the oximes and OPCs were $15 \mu \mathrm{M}$ and $1.5 \mathrm{mM}$, respectively, i.e. the oxime to OPC ratio was 1:100. In the spectral region of interest neither MOPS buffer nor the OPCs showed any absorbance. The peak absorbance in the region of interest $(250 \mathrm{~nm}-400 \mathrm{nM})$, representing the zwitterionic (betaine) form of the oxime (Schoene 1973; Waser et al. 1992), was used for quantification and calculation of the decomposition halflife times $t_{1 / 2}$, the first-order rate constants $k_{1}$, the second-order rate constants $k_{2}$, and the maximum reaction velocities $v_{\max }$ at the reactant concentrations indicated.

\section{Calculations}

The semilogarithmic plot of oxime concentrations versus time showed a straight line indicating a monomolecular reaction (pseudo-first-order kinetics). After the graphic determination of the half-life time $t_{1 / 2}$ the firstorder rate constant $k_{1}$ is available, since at that point of time the initial oxime concentration is reduced to $1 / 2$ :

$$
k_{1} \times t_{1 / 2}=-\ln 1 / 2=-2.303 \log 1 / 2
$$


$t_{1 / 2}=-1 / k_{1} \times 2.303 \times(-0.301)=0.693 / k_{1}(\mathrm{~min})$

for practical use: $k_{1}=0.693 / t_{1 / 2}\left(\mathrm{~min}^{-1}\right)$

$k_{1}$ leads to the second-order rate constant $k_{2}$ :

$k_{2}=k_{1} /($ initial OPC concentration $)=k_{1} / 1.5 \times 10^{-3}$ $\left(\mathrm{M}^{-1} \min ^{-1}\right)$

By means of $k_{2}$ the maximum reaction velocity can be calculated:

$\mathrm{v}_{\max }=k_{2} \times($ oxime concentration $) \times(\mathrm{OPC}$ concentration) $\left(\mathrm{M} \mathrm{min}^{-1}\right)$

$v_{\max }=k_{2} \times\left(15 \times 10^{-6}\right) \times\left(1.5 \times 10^{-3}\right)\left(\mathrm{M} \mathrm{min}^{-1}\right)$

for practical use: $v_{\text {max }}=k_{2} \times 22.5 \times 10^{-9} \quad(\mathrm{M}$ $\min ^{-1}$ )

All kinetic parameters summarized in Table 1 were calculated this way.

\section{Results}

The direct reaction of the oxime HI 6 and crotylsarin is shown in Fig. 1. The spectrum of HI 6 (reference in the absence of crotylsarin) is characterized by three maxima at 273, 300, and $354 \mathrm{~nm}$, respectively. After addition of an 100-fold excess of crotylsarin, a marked but transient increase of the peak at $273 \mathrm{~nm}$ over a period of $10 \mathrm{~min}$ could be observed, whereas the two other maxima decreased. The half-time of HI 6 concentration decrease was $3.7 \mathrm{~min}$ according the diminution of the zwitterion peak at $354 \mathrm{~nm}$.

Figure 2 shows the direct reaction of HI 6 and VX. It is obvious that the change of the HI 6 spectrum was different, compared to the experiments with crotylsarin. The maxima at 300 and $354 \mathrm{~nm}$ decreased similar to the experiments with crotylsarin, whereas the peak at $273 \mathrm{~nm}$ was transformed into a shoulder. On the basis of the decreasing absorbances at $354 \mathrm{~nm}$ the halflife time of HI 6 decrease was determined to be $16.4 \mathrm{~min}$.

The spectrum of 2-PAM (reference in the absence of cyclosarin) displays a peak at $294 \mathrm{~nm}$ and a shoulder (zwitterion) at $330 \mathrm{~nm}$ (Fig. 3). After addition of an 100 -fold excess of cyclosarin the maximum and the shoulder decreased with increasing reaction time. The

Table 1 Decomposition half-lifes $\left(t_{1 / 2}\right)$, rate constants $\left(k_{1}, k_{2}\right)$, and maximum reaction velocities $\left(v_{\max }\right)$ of different oximes $(15 \mu \mathrm{M})$ in the presence of $1.5 \mathrm{mM}$ of crotylsarin, cyclosarin, or VX in $0.1 \mathrm{M}$ MOPS buffer, pH 7.4 at $25^{\circ} \mathrm{C}$

\begin{tabular}{|c|c|c|c|c|c|}
\hline Oxime & Poison & $t_{1 / 2}(\min )$ & $k_{1}\left(\min ^{-1}\right)$ & $k_{2}\left(\mathrm{M}^{-1} \min ^{-1}\right)$ & $v_{\max }\left(\mathrm{M} \mathrm{min}^{-1}\right)$ \\
\hline \multirow[t]{3}{*}{ 2-PAM iodide $(\lambda=294 \mathrm{~nm})$} & Crotylsarin & 5.3 & 0.1307 & 87.2 & $1.961 \times 10^{-6}$ \\
\hline & Cyclosarin & 7.5 & 0.0924 & 61.6 & $1.386 \times 10^{-6}$ \\
\hline & VX & 66 & 0.0105 & 7.0 & $0.158 \times 10^{-6}$ \\
\hline \multirow[t]{3}{*}{ 2-PAM iodide $(\lambda=326 \mathrm{~nm})$} & Crotylsarin & 3.9 & 0.1777 & 118.4 & $2.664 \times 10^{-6}$ \\
\hline & Cyclosarin & 6.0 & 0.1155 & 77.0 & $1.733 \times 10^{-6}$ \\
\hline & VX & 76 & 0.0091 & 6.1 & $0.137 \times 10^{-6}$ \\
\hline \multirow[t]{3}{*}{ Obidoxime $(\lambda=354 \mathrm{~nm})$} & Crotylsarin & 3.5 & 0.1980 & 132.0 & $2.970 \times 10^{-6}$ \\
\hline & Cyclosarin & 5.8 & 0.1195 & 79.7 & $1.793 \times 10^{-6}$ \\
\hline & VX & 42.5 & 0.0163 & 10.9 & $0.245 \times 10^{-6}$ \\
\hline \multirow[t]{3}{*}{$\operatorname{HS} 6(\lambda=354 \mathrm{~nm})$} & Crotylsarin & 4.2 & 0.1650 & 110.0 & $2.475 \times 10^{-6}$ \\
\hline & Cyclosarin & 8.0 & 0.0866 & 57.7 & $1.298 \times 10^{-6}$ \\
\hline & VX & 20.2 & 0.0343 & 22.9 & $0.515 \times 10^{-6}$ \\
\hline \multirow[t]{3}{*}{$\operatorname{HGA} 1(\lambda=340 \mathrm{~nm})$} & Crotylsarin & 5.9 & 0.1174 & 78.3 & $1.761 \times 10^{-6}$ \\
\hline & Cyclosarin & 10.9 & 0.0636 & 42.4 & $0.954 \times 10^{-6}$ \\
\hline & VX & $>540$ & - & - & - \\
\hline \multirow[t]{3}{*}{ HGG 12 chloride $(\lambda=356 \mathrm{~nm})$} & Crotylsarin & 4.8 & 0.1443 & 96.2 & $2.165 \times 10^{-6}$ \\
\hline & Cyclosarin & 7.6 & 0.0912 & 60.8 & $1.368 \times 10^{-6}$ \\
\hline & VX & 24.6 & 0.0282 & 18.8 & $0.423 \times 10^{-6}$ \\
\hline \multirow[t]{3}{*}{ HGG 12 nitrate $(\lambda=356 \mathrm{~nm})$} & Crotylsarin & 4.4 & 0.1575 & 105.0 & $2.362 \times 10^{-6}$ \\
\hline & Cyclosarin & 6.8 & 0.1019 & 67.9 & $1.528 \times 10^{-6}$ \\
\hline & VX & 26.8 & 0.0258 & 17.2 & $0.387 \times 10^{-6}$ \\
\hline \multirow[t]{3}{*}{ HI $6(\lambda=354 \mathrm{~nm})$} & Crotylsarin & 3.7 & 0.1873 & 124.9 & $2.809 \times 10^{-6}$ \\
\hline & Cyclosarin & 5.9 & 0.1175 & 78.3 & $1.762 \times 10^{-6}$ \\
\hline & VX & 16.4 & 0.0422 & 28.2 & $0.630 \times 10^{-6}$ \\
\hline \multirow[t]{3}{*}{ HLö $7(\lambda=354$ nm $)$} & Crotylsarin & 6.7 & 0.1034 & 68.9 & $1.551 \times 10^{-6}$ \\
\hline & Cyclosarin & 10.5 & 0.0660 & 44.0 & $0.990 \times 10^{-6}$ \\
\hline & VX & $>540$ & - & - & - \\
\hline \multirow[t]{3}{*}{ HLö $7(\lambda=379$ nm $)$} & Crotylsarin & 9.1 & 0.0761 & 50.8 & $1.142 \times 10^{-6}$ \\
\hline & Cyclosarin & 12.2 & 0.0568 & 37.9 & $0.853 \times 10^{-6}$ \\
\hline & VX & 151 & 0.0046 & 3.1 & $0.070 \times 10^{-6}$ \\
\hline
\end{tabular}

Calculations are on the basis of the absorbances at the wavelengths indicated in parentheses. The full chemical name of the oximes is given in Materials and methods 


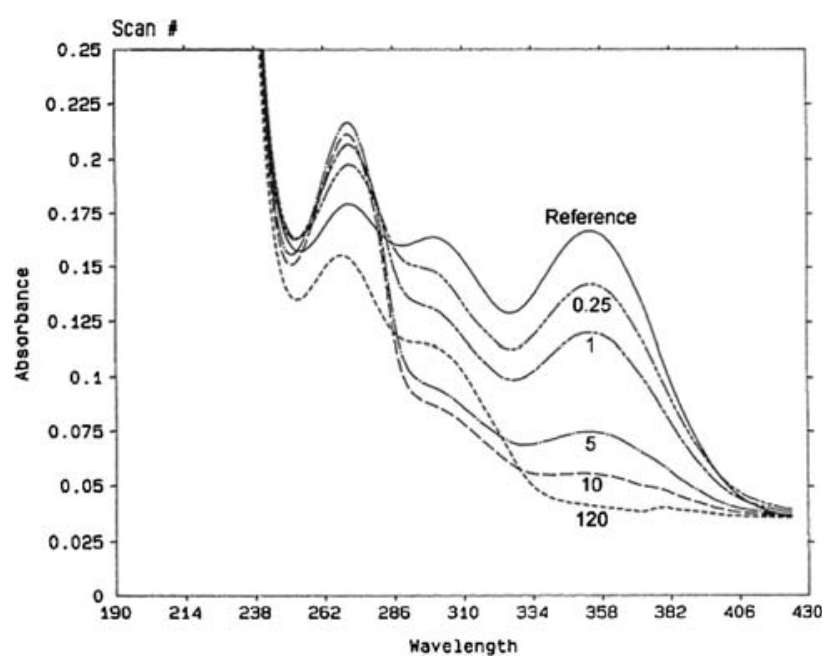

Fig. 1 Time related spectral changes of a mixture of HI $6(15 \mu \mathrm{M})$ and crotylsarin $(1.5 \mathrm{mM})$ in $0.1 \mathrm{M}$ MOPS buffer, $\mathrm{pH} 7.4$ at $25^{\circ} \mathrm{C}$. Time of recording relative to the reaction start by mixing of the components (HI 6, $30 \mu \mathrm{M}+$ crotylsarin, $3 \mathrm{mM}$, in $0.1 \mathrm{M}$ MOPS buffer, $1.5 \mathrm{ml}$ each) given in minutes. For the full chemical name of the oxime see Materials and methods

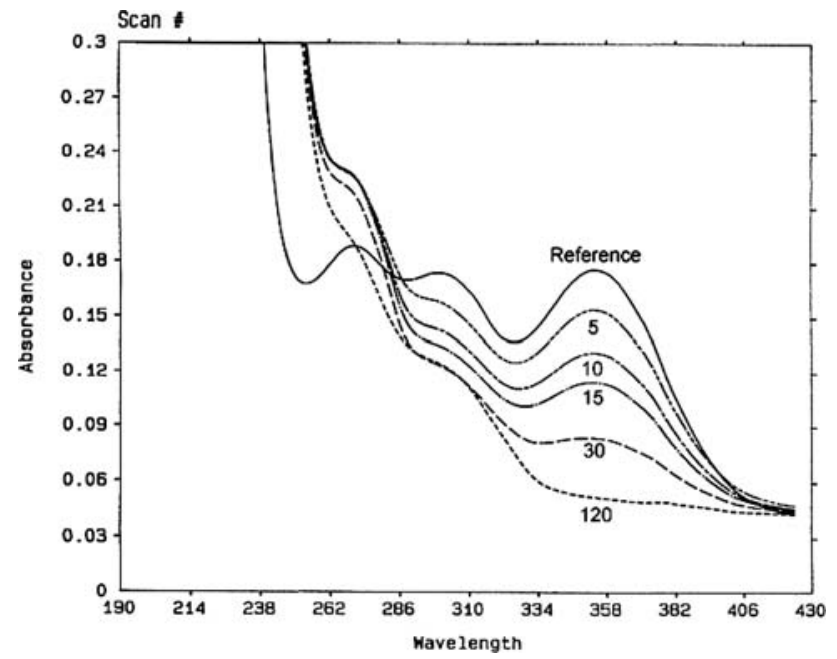

Fig. 2 Time related spectral changes of a mixture of HI $6(15 \mu \mathrm{M})$ and VX $(1.5 \mathrm{mM})$ in $0.1 \mathrm{M}$ MOPS buffer, $\mathrm{pH} 7.4$ at $25^{\circ} \mathrm{C}$. Time of recording relative to the reaction start by mixing of the components (HI 6, $30 \mu \mathrm{M}+\mathrm{VX}, 3 \mathrm{mM}$, in $0.1 \mathrm{M}$ MOPS buffer, $1.5 \mathrm{ml}$ each) given in minutes. For the full chemical name of the oxime see Materials and methods

peak at $294 \mathrm{~nm}$ showed a hypsochromic shift during the incubation time, while the shoulder was stationary. The half-life time of 2-PAM was $7.5 \mathrm{~min}(294 \mathrm{~nm})$ or $6.0 \mathrm{~min}(326 \mathrm{~nm})$, respectively.

The experimental results and the calculated kinetic parameters are summarized in Table 1 . As the dimension $\left(\min ^{-1}\right)$ of $k_{1}$ in Table 1 shows, this value characterizes the decay of a substance (OPC) per minute. The first-order rate constant $k_{1}$ is independent of the con-

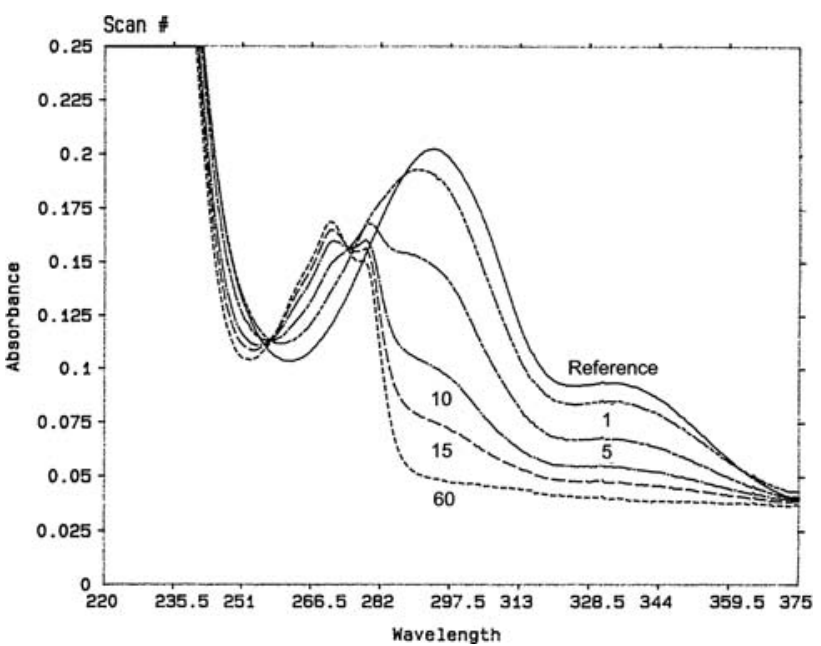

Fig. 3 Time related spectral changes of a mixture of 2-PAM $(15 \mu \mathrm{M})$ and cyclosarin $(1.5 \mathrm{mM})$ in $0.1 \mathrm{M}$ MOPS buffer, $\mathrm{pH} 7.4$ at $25^{\circ} \mathrm{C}$. Time of recording relative to the reaction start by mixing of the components (2-PAM, $30 \mu \mathrm{M}+$ cyclosarin, $3 \mathrm{mM}$, in $0.1 \mathrm{M}$ MOPS buffer, $1.5 \mathrm{ml}$ each) given in minutes. For the full chemical name of the oxime see Materials and methods

centration. The multiplication of $k_{1}$ with 100 gives the percentage of decay per minute; for example, the first line in Table 1 shows a $k_{1}$ value of $0.1307 \mathrm{~min}^{-1}$, that means a disappearance per minute of $13.07 \%$ of crotylsarin. In contrast to $k_{1}$ the second-order rate constant $k_{2}$ is dependent on the concentration. The knowledge of $k_{2}$ is necessary for the calculation of the maximum reaction velocity $v_{\text {max }}$. This parameter cannot be exceeded and describes the maximum quantity of a substance (moles per litre) that react per minute.

It can be taken from Table 1 that the reaction velocities increased in the order $\mathrm{VX}<$ cyclosarin $<$ crotylsarin. The reaction of VX and HGA 1 was too slow $\left(t_{1 / 2}>540 \mathrm{~min}\right)$ to calculate a half-time. Even the doubling of the VX concentration from 1.5 to $3.0 \mathrm{mM}$ did not increase the reaction velocity. The same phenomenon was to be observed $\left(t_{1 / 2}>540 \mathrm{~min}\right)$ with the reaction of VX and HLö 7 (354 nm; Table 1).

\section{Discussion}

The results indicate that the oximes investigated react spontaneously with the three OPCs. The reaction velocities, however, were markedly different. The sarin analogues showed high reaction velocities with halftimes of the oximes between 3.5 and 9.1 min (crotylsarin) and between 5.8 and $12.2 \mathrm{~min}$ (cyclosarin). In contrast, the decrease of the oxime concentration was much slower in the presence of VX (half-times 
between 16.4 and $151 \mathrm{~min}$ ). In two cases, HGA 1 at $340 \mathrm{~nm}$ and HLÖ 7 at $354 \mathrm{~nm}$, the direct reaction with VX was too slow to calculate half-lifes of the oximes $\left(t_{1 / 2}>540 \mathrm{~min}\right)$. The explanation might be that the leaving group of the sarin analogues is the small fluoride ion (MW ca. $19 \mathrm{Da}$ ) whereas the leaving group of VX (the anion of diisopropylaminothioethanol) shows more than the eightfold mass (MW ca. $160 \mathrm{Da}$ ). Other reasons for the different behaviour of the sarin analogues and VX might be different water solubility, different electron density at the $\mathrm{P}$-atome, and steric factors.

The direct reaction is accomplished at least in three steps, (a) generation of the oxime zwitterion (betaine), (b) formation of a phosphyloxime (POX) intermediate, and (c) irreversible decomposition of the POX into less toxic compounds (Steinberg and Solomon 1966). POXs were identified as highly toxic anticholinesterases, even 10- to 100-fold more toxic than their parent compounds (Hackley et al. 1959; Lamb et al. 1964, 1965; Schoene 1973; Nenner 1974; de Jong and Ceulen 1978; Harvey et al. 1984, 1986; Worek et al. 2000). The stability of the POX intermediate seems to be an important factor determining the velocity of the direct reaction. During the reaction of HI 6 and crotylsarin, an immediate increase followed by a diminution of the peak at $273 \mathrm{~nm}$ was observed (Fig. 1). This could be interpreted as formation and degradation of a metastable transition state complex in which the POX and other reaction products are involved. In the same way the alteration of the HI 6 spectrum at $273 \mathrm{~nm}$ during the reaction with VX (Fig. 2) and the marked hypsochromic shift during the reaction of 2-PAM and cyclosarin (Fig. 3) could be explained.

Recently, Ashani et al. (2003) reported upon the distinctive properties of the POXs formed from 2-, 3-, and 4-PAM with different OPCs (e.g. sarin, cyclosarin, soman, tabun, VX). The $t_{1 / 2}$ values of the non-enzymatic decomposition of the 2-PAM POXs ranged from 0.7 to $1.5 \mathrm{~min}$. We observed similar half-lifes from 3.9 to $7.5 \mathrm{~min}$ for the complete direct reaction (formation and decomposition of the POXs) of cyclo- or crotylsarin with 2-PAM. However, our results obtained with 2PAM and VX at 294 and $326 \mathrm{~nm}$ show much higher values $\left(t_{1 / 2}>60 \mathrm{~min}\right)$. The reason for this difference might be the leaving group effect during POX formation mentioned above. Furthermore, it must be taken in account that Ashani et al. (2003) worked with highly diluted HEPES buffer $(0.01 \mathrm{M})$, $\mathrm{pH} 7.8$ at $29^{\circ} \mathrm{C}$. The concentration of the POXs was in the order of magnitude of $0.05 \mathrm{mM}(=50 \mu \mathrm{M})$ as described in an earlier paper of this group (Leader et al. 1999). Compared to the conditions we used (0.1 M MOPS buffer, $\mathrm{pH} 7.4$ at $25^{\circ} \mathrm{C} ; 15 \mu \mathrm{M}$ oxime and $1.5 \mathrm{mM}$ nerve agent), the different buffer type and buffer concentration, $\mathrm{pH}$ value, and reaction temperature may have an accelerating effect on the decomposition velocity of the POXs and may explain the short half-times given by Ashani et al. (2003).

The question whether the direct reaction could contribute to the detoxication of nerve agents in vivo during OPC poisoning can be evaluated by means of the maximum reaction velocities $\left(v_{\max }\right)$ in Table 1 . These values reach from $0.070 \times 10^{-6}$ to $2.970 \times$ $10^{-6} \mathrm{M} \mathrm{min}^{-1}$, hence, the pair HLö 7/VX shows the lowest and the combination obidoxime/crotylsarin the highest reaction velocity (Table 1 ). It can be assumed that during poisoning the OPC concentration in vivo is in the nanomolar range and the reasonable therapeutic concentration of an oxime is approximately $15 \mu \mathrm{M}$. Under these conditions the maximum reaction velocities are $v_{\max }=0.465 \times 10^{-12} \mathrm{M} \mathrm{min}^{-1}$ (at $10 \mathrm{nM} \mathrm{VX}$ and $15 \mu \mathrm{M} \mathrm{HI} 6$ ) and $v_{\max }=19.80 \times 10^{-12} \mathrm{M} \mathrm{min}^{-1}$ (at $10 \mathrm{nM}$ crotylsarin and $15 \mu \mathrm{M}$ obidoxime).

The $v_{\max }$ values of all the other OPC oxime combinations in Table 1 are to be found within this range. These results are in agreement with a previous study (Becker et al. 1997) using soman/HI 6. In this case the maximum reaction velocity was calculated to be $v_{\max }=2.55 \times 10^{-12} \mathrm{M} \mathrm{min}^{-1}$ (at $10 \mathrm{nM}$ soman and $15 \mu \mathrm{M}$ HI 6). This order of magnitude (picomoles per litre) demonstrates that the direct reaction cannot markedly contribute to the therapeutic effect of oximes in vivo.

\section{Conclusion}

The results presented here with crotyl- and cyclosarin demonstrate that the direct reaction of OPCs and pyridinium oximes could be used for mild decontamination/detoxication purposes (skin, mucous membranes, wounds). Pyridinium oximes could substitute the efficient but corrosive preparations of hypochlorites $(\mathrm{NaOCl}$ solution, calcium hypochlorite/magnesium oxide powder). This holds true for previously published data obtained with sarin, soman, and tabun (Becker et al. 1997). For practical administrations it might be useful to accelerate the third step of the direct reaction, i.e., the degradation of the POXs, by addition of bacterial (Ashani et al. 1998; Leader et al. 1999; Herkenhoff et al. 2004) or human plasma enzymes (Kiderlen et al. 2000; Worek et al. 2000).

The importance of the direct reaction in the detoxication during human OPC poisoning may be assessed by considering the generated data (Table 1 ) and by 
regarding the concentrations of OPCs and oximes, which can be expected in human OPC poisoning. Hence, the maximum reaction velocity was calculated to be in the range of $10^{-12} \mathrm{M} \mathrm{min}^{-1}$ (picomoles per litre). This demonstrates that in vivo the direct reaction is only of small significance. However, it can be considered as a beneficial side effect to the oxime action in vivo.

\section{References}

Ashani Y, Bhattacharjee AK, Leader H, Saxena A, Doctor BP (2003) Inhibition of cholinesterases with cationic phosphonyl oximes highlights distinctive properties of the charged pyridine groups of quaternary oxime reactivators. Biochem Pharmacol 66:191-202

Ashani Y, Leader H, Rothschild N, Dosoretz C (1998) Combined effect of organosphosphorus hydrolase and oxime on the reactivation rate of diethylphosphoryl-acetylcholinesterase conjugates. Biochem Pharmacol 55:159-168

Becker G, Kawan A, Szinicz L (1997) Direct reaction of oximes with sarin, soman, or tabun in vitro. Arch Toxicol 71:714-718

De Jong LPA, Ceulen DJ (1978) Anticholinesterase activity and rate of decomposition of some phosphylated oximes. Biochem Pharmacol 27:857-863

Green AL, Saville B (1956) The reaction of oximes with isopropyl methylphosphonofluoridate (sarin). J Chem Soc 27:38873892

Hackley BE, Steinberg GM, Lamb JC (1959) Formation of potent inhibitors of $\mathrm{AChE}$ by reaction of pyridinealdoximes with isopropyl methylphosphonofluoridate (GB). Biochim Biophys Acta 80:211-214

Harvey B, Sellers DJ, Watts P (1984) The reactivation by oximes of phosphonylated acetylcholinesterase: the possible erroneous interpretation of reactivating potency. Biochem Pharmacol 33:3499-3501

Harvey B, Scott RP, Sellers DJ, Watts P (1986) In vitro studies on the reactivation by oximes of phosphylated acetylcholinesterase. I. On the reactions of P2S with various organophos- phates and the properties of the resultant phosphylated oximes. Biochem Pharmacol 35:737-744

Herkenhoff S, Szinicz L, Rastogi VR, Cheng TC, DeFrank JJ, Worek F (2004) Effect of organophosphorus hydrolysing enzymes on obidoxime-induced reactivation of organophosphate-inhibited human acetylcholinesterase. Arch Toxicol 78:338-343

Kiderlen D, Worek F, Klimmek R, Eyer P (2000) The phosphoryl oxime-destroying activity of human plasma. Arch Toxicol 74:27-32

Lamb JC, Steinberg GM, Hackley BE (1964) Isopropyl methylphosphonylated bisquaternary oximes: powerful inhibitors of cholinesterases. Biochim Biophys Acta 89:174-176

Lamb JC, Steinberg GM, Solomon S, Hackley BE (1965) Reaction of 4-formyl-1-methylpyridinium iodide oxime with isopropyl methylphosphonofluoridate. Biochemistry 4:2475-2484

Leader H, Vincze A, Manisterski B, Rothschild N, Dosoretz C, Ashani Y (1999) Characterization of O,O-diethylphosphoryloximes as inhibitors of cholinesterases and substrates of phosphotriesterases. Biochem Pharmacol 58:503-515

Lee EC (2003) Clinical manifestations of sarin nerve gas exposure. JAMA 290:659-662

Nenner M (1974) Phosphonylierte Aldoxime. Hemmwirkung auf Acetylcholinesterase und hydrolytischer Abbau. Biochem Pharmacol 23:1255-1262

Okonek S (1972) GC-Analyse der Direktreaktion von Soman und Paraoxon mit Pyridinium-aldoximen in vitro. Arch Toxicol 29:255-264

Schoene K (1973) Phosphonyloxime aus Soman; Bildung und Reaktion mit Acetylcholin-esterase in vitro. Biochem Pharmacol 22:2997-3003

Steinberg GM, Solomon S (1966) Decomposition of a phosphonylated pyridinium aldoxime in aqueous solution. Biochemistry 5:3142-3150

Volans AP (1996) Sarin: guidelines on the management of victims of a nerve gas attack. J Accid Emerg Med 13:202-206

Waser PG, Alioth-Streichenberg CM, Hopff WH, Portmann R, Hofmann W, Niederhauser A (1992) Interaction of obidoxime with sarin in aqueous solution. Arch Toxicol 66:211-215

Worek F, Eyer P, Kiderlen D, Thiermann H, Szinicz L (2000) Effect of human plasma on the reactivation of sarin-inhibited human erythrocyte acetylcholinesterase. Arch Toxicol $74: 21-26$ 